\title{
Axial Ligand-Engineered Single-Atom Catalysts with Boosted Enzyme-Like Activity for Sensitive Immunoassay
}

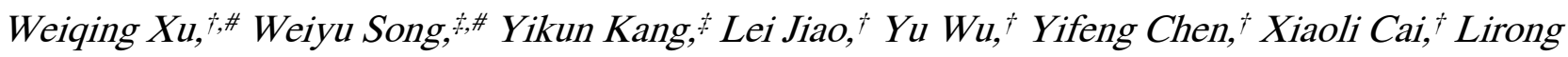 \\ Zheng, ${ }^{\S}$ Wenling Gu, ${ }^{\dagger}$ Chengzhou $Z \mathrm{Zh}^{\dagger}$ **
}

† Key Laboratory of Pesticide and Chemical Biology of Ministry of Education, International Joint Research Center for Intelligent Biosensing Technology and Health, College of Chemistry, Central China Normal University, Wuhan, 430079, P.R. China

Email:czzhu@mail.ccnu.edu.cn

¥State Key Laboratory of Heavy Oil Processing, College of New Energy and Materials

China University of Petroleum, Beijing 102249, P.R. China

§Beijing Synchrotron Radiation Facility, Institute of High Energy Physics, Chinese Academy of Sciences, Beijing 100049, P.R. China 


\section{Materials and Instruments}

Materials: Graphene was obtained from Nanjing XFnano Technology Co., Ltd. Dicyandiamide (DICY), hemin, cytochrome C (Cyt-C), glucose oxidase (GOx) and glucose were purchased from Shanghai Aladdin Bio-Chem Technology Co., Ltd. 3,3',5,5'-tetramethylbenzidine (TMB) was obtained from Shanghai Dibai Biotechnology Co., Ltd. 1-Ethyl-3-(3-dimethylaminopropyl) carbodiimide hydrochloride (EDC) and N-hydroxysuccinimide (NHS) was from Shanghai Medpep Co., Ltd. Fluorescein isothiocyanate (FITC), and bovine serum albumin (BSA) were from Sigma-Aldrich. Phosphate buffered saline (PBS) was purchased from Boster Biological Technology Co., Ltd. The antibodies and antigens of carcinoembryonic antigen (CEA), prostate-specific antigen (PSA) estrogen receptor (ER), progesterone receptor (PR) and human epidermal growth factor receptor-2 (HER2) were purchased from Sangon Biotech (Shanghai) Co., Ltd. Enzyme labelled antibody of CEA was purchased from Shanghai Linc-Bio Co., Ltd. Other chemical reagents were purchased from Sinopharm Chemical Reagent Co., Let (Shanghai, China).

Instruments: Transmission electron microscopy (TEM) studies were performed by using an FEI Titan G2 60-300 (super-x). Scanning electron microscopy (SEM) images were obtained from the Gemini SEM 300 (ZEISS). The aberration-corrected high-angle annular dark-field scanning transmission electron microscopy (AC-HAADF-STEM) was performed by a Titan G2-600 (FEI, Unites States). Atomic force microscopy (AFM) images were taken with a NanoManVS instrument. X-ray absorption near-edge structure (XANES) and extended X-ray absorption fine structure (EXAFS) experiments on a Fe K-edge were obtained from 1W1B station in Beijing Synchrotron Radiation Facility (BSRF). All Raman spectra were recorded by the laser Raman spectrophotometer (Thermo Fisher, USA). The element contents were obtained by inductively coupled plasma optical emission (ICP-OES) spectrometry (Agilent 8800). Powder X-ray diffraction (XRD) patterns were carried using a Tensor 27. X-ray photoelectron spectroscopy (XPS) measurements were used by a VG Multilab 2000 (Thermo Fisher, USA). Electron paramagnetic resonance (EPR) measurements were obtained by an EMXmicro-6/1 (Bruker, Germany). Ultrapure water was obtained from a Milli-Q purification system (Millipore, MA, USA). Confocal laser scanning microscopy (CLSM) experiment was utilized a Leica TCS SP8 microscope. All the absorbance and fluorescence spectra were obtained from a multimode reader (Tecan Spark, Switzerland).

\section{Experiment Section}

\subsection{The Specific Activity kinetics assay of SACs}

The specific activity (SA) is defined as activity units (U) per milligram of catalysts. The evaluation method of activity units of catalysts was using the following equation (1), which was based on the previous reference. 


$$
\mathrm{b}_{\text {catalysts }}=\frac{\mathrm{V} \times\left(\frac{\Delta \mathrm{A}}{\Delta \mathrm{\Delta t}}\right)}{\varepsilon \times 1}
$$

$b_{\text {catalysts }}$ is the catalytic activity of catalysts expressed in units. $\mathrm{V}$ is the total volume of the reaction solution $(\mu \mathrm{L}) ; \varepsilon$ is the molar absorption coefficient of the colorimetric TMB $\left(39,000\left(\mathrm{M}^{-1} \mathrm{~cm}^{-1}\right) .1\right.$ is the path length of light traveling (cm); $\mathrm{A}$ is the absorbance value; and $\Delta \mathrm{A} / \Delta \mathrm{t}$ is the initial rate of change in absorbance at $652 \mathrm{~nm} \mathrm{~min}{ }^{-1}$.

The SA of the catalysts was calculated by using the following equation (2)

$$
\mathrm{a}_{\text {catalysts }}=\mathrm{b}_{\text {catalysts }} /[\mathrm{m}]
$$

$[\mathrm{m}]$ is the quality of catalysts (mg).

The kinetics assay of these prepared catalysts was studied for their catalytic ability. Firstly, as for the kinetic data toward TMB, $0.2 \mathrm{mg} \mathrm{mL}^{-1} \mathrm{NG}-\mathrm{Heme}$ or $0.18 \mathrm{mg} \mathrm{mL}^{-1} \mathrm{G}-\mathrm{Heme}(5 \mu \mathrm{L})$ was introduced into the HAc-NaAc buffer $(\mathrm{pH}$ 3.5, $150 \mu \mathrm{L})$ containing $500 \mathrm{mM} \mathrm{H}_{2} \mathrm{O}_{2}(100 \mu \mathrm{L})$ and different concentration TMB $(50 \mu \mathrm{L})$. Secondly, as for the kinetic data toward $\mathrm{H}_{2} \mathrm{O}_{2}, 0.2 \mathrm{mg} \mathrm{mL}^{-1}$ catalysts $(5 \mu \mathrm{L})$ was added into the HAc-NaAc buffer ( $\left.\mathrm{pH} 3.5,150 \mu \mathrm{L}\right)$ containing 10 mM TMB $(50 \mu \mathrm{L})$ and different concentration $\mathrm{H}_{2} \mathrm{O}_{2}(100 \mu \mathrm{L})$. Then, the Michaelis-Menten equation $\left(\mathrm{V}=\mathrm{V}_{\max }[\mathrm{S}] /\left(\mathrm{K}_{\mathrm{m}}\right.\right.$ $+[\mathrm{S}])$ ) was used to analyze the kinetics date of catalysts. The $\mathrm{v}$ is the initial velocity, $\mathrm{V}_{\max }$ is the maximal reaction velocity, [S] is the concentration of the substrate, and $\mathrm{K}_{\mathrm{m}}$ is the Michaelis-Menten constant.

\subsection{Colorimetric immunoassays of CEA}

Firstly, $1 \mu \mathrm{g} \mathrm{mL} \mathrm{m}^{-1}$ capture antibody $\left(\mathrm{Ab}_{1}, 100 \mu \mathrm{L}\right)$ standard was added in the 96-well plates to incubate overnight at $4{ }^{\circ} \mathrm{C}$. Secondly, after each well was washed with PBS $(200 \mu \mathrm{L})$ three times and $1 \%$ BSA (100 $\left.\mu \mathrm{L}\right)$ was allowed to block antibody-free sites. After being shaken and incubated for $1.5 \mathrm{~h}$ at $37{ }^{\circ} \mathrm{C}$, the redundant BSA was removed by washing with PBS three times. Thirdly, various concertation $(1,2,5,8,10,20,50,80,100,200,500,800,1000 \mathrm{pg}$ $\left.\mathrm{mL}^{-1}\right)$ of antigen $(100 \mu \mathrm{L})$ was added into the $\mathrm{Ab}_{1}$-coated wells and incubated at $37^{\circ} \mathrm{C}$ for $1.5 \mathrm{~h}$. Fourthly, each well was washed with PBS three times and incubated with the prepared NG-Heme-Ab $(100 \mu \mathrm{L})$ to especially combine with antigen. After incubation for $1.5 \mathrm{~h}$ at $37{ }^{\circ} \mathrm{C}$, the free $\mathrm{NG}-\mathrm{Heme}-\mathrm{Ab}_{2}$ was removed with PBS six times. Finally,

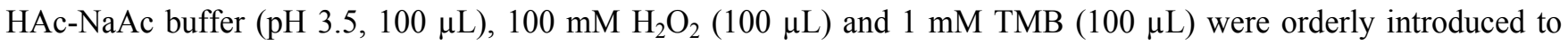
induce the colorimetric reaction. After incubation and shaken for $15 \min 37^{\circ} \mathrm{C}$, the absorbance of the reaction solution was recorded with a multimode reader.

As a control, the commercial HRP-labeled $\mathrm{Ab}_{2}$ was also utilized to determine the concentration of CEA. The procedure of detection was the same as the abovementioned, except that the NG-Heme-Ab $b_{2}$ was replaced by the HRP-labeled $\mathrm{Ab}_{2}\left(10 \mu \mathrm{g} \mathrm{mL} \mathrm{mL}^{-1}\right)$.

\subsection{Assay of the CEA in human serum}


On the one hand, the different concentrations of standard samples were prepared through the standard addition method, where the various amounts of CEA were added into the healthy human serum, which was diluted 100 times with PBS buffer ( $\mathrm{pH}$ 7.4). On the other hand, some human serum samples were obtained from Zhengzhou people's hospital (Zhengzhou, China) with written consent from all patients. Before assay the concentration of CEA, the human serum samples were diluted 100 times. The detection process of the practical samples was to the above process. 


\section{Figures and Tables}
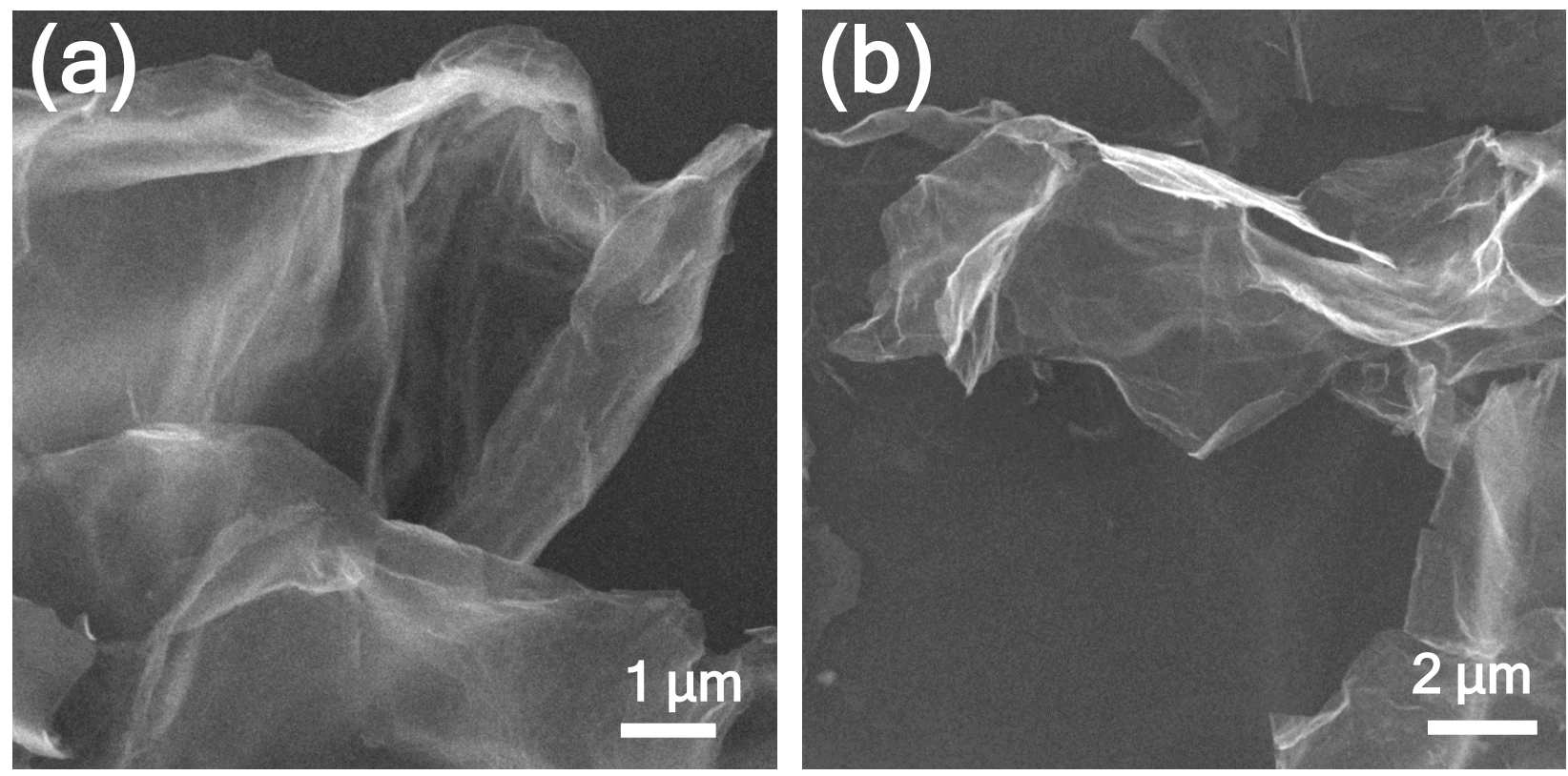

Figure S1. SEM images of (a) G-Heme and (b) NG-Heme.

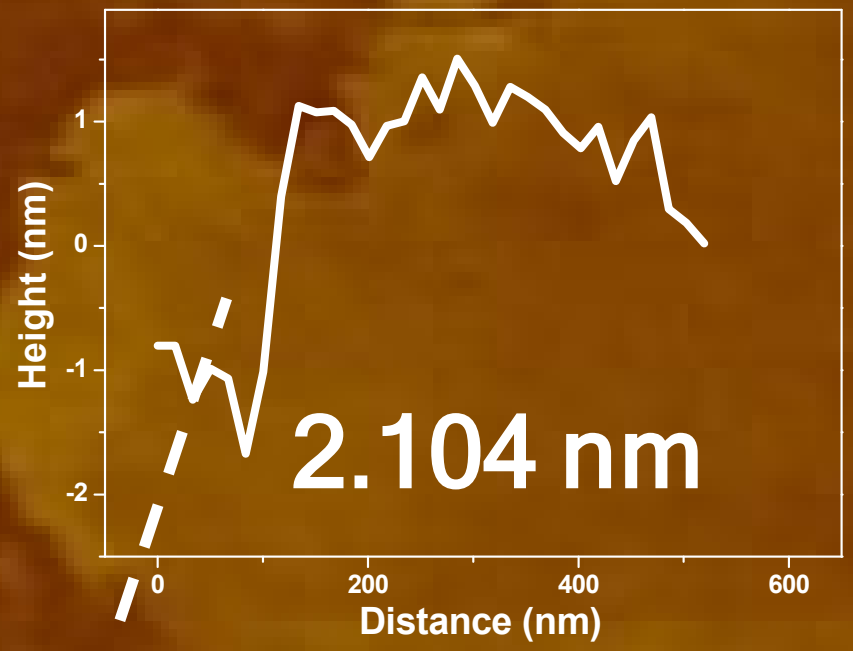

$200 \mathrm{~nm}$

Figure S2. AFM image of G-Heme. 


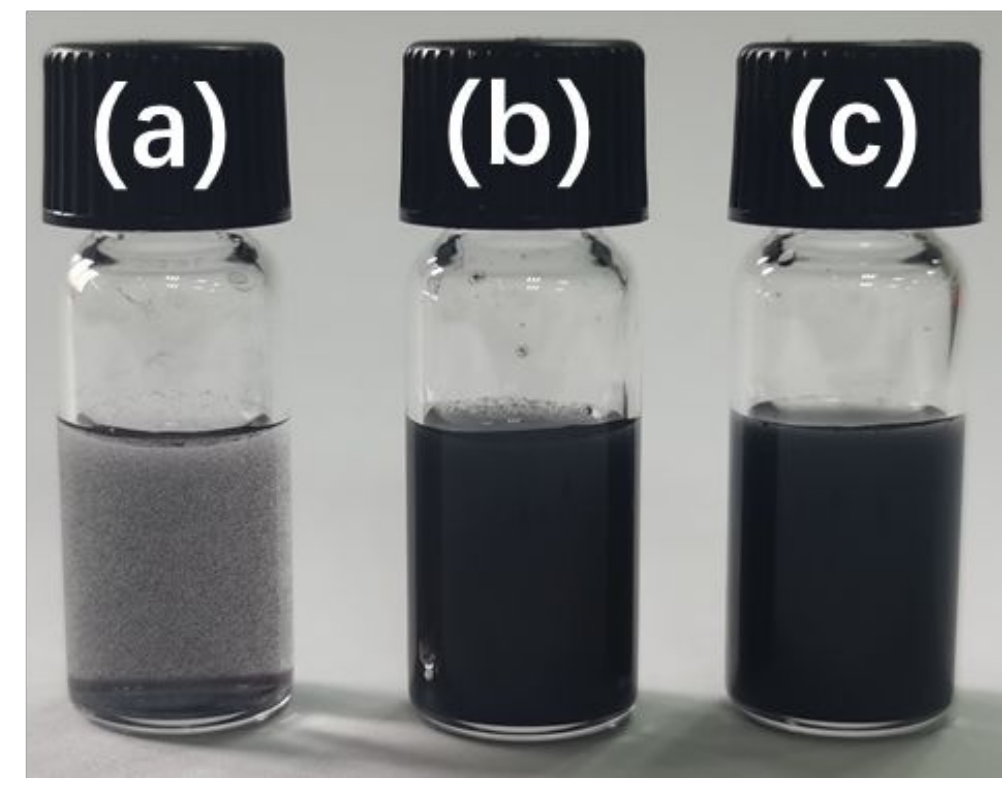

Figure S3. Digital image of (a) hemin, (b) G-Heme and (c) NG-Heme in aqueous solution.

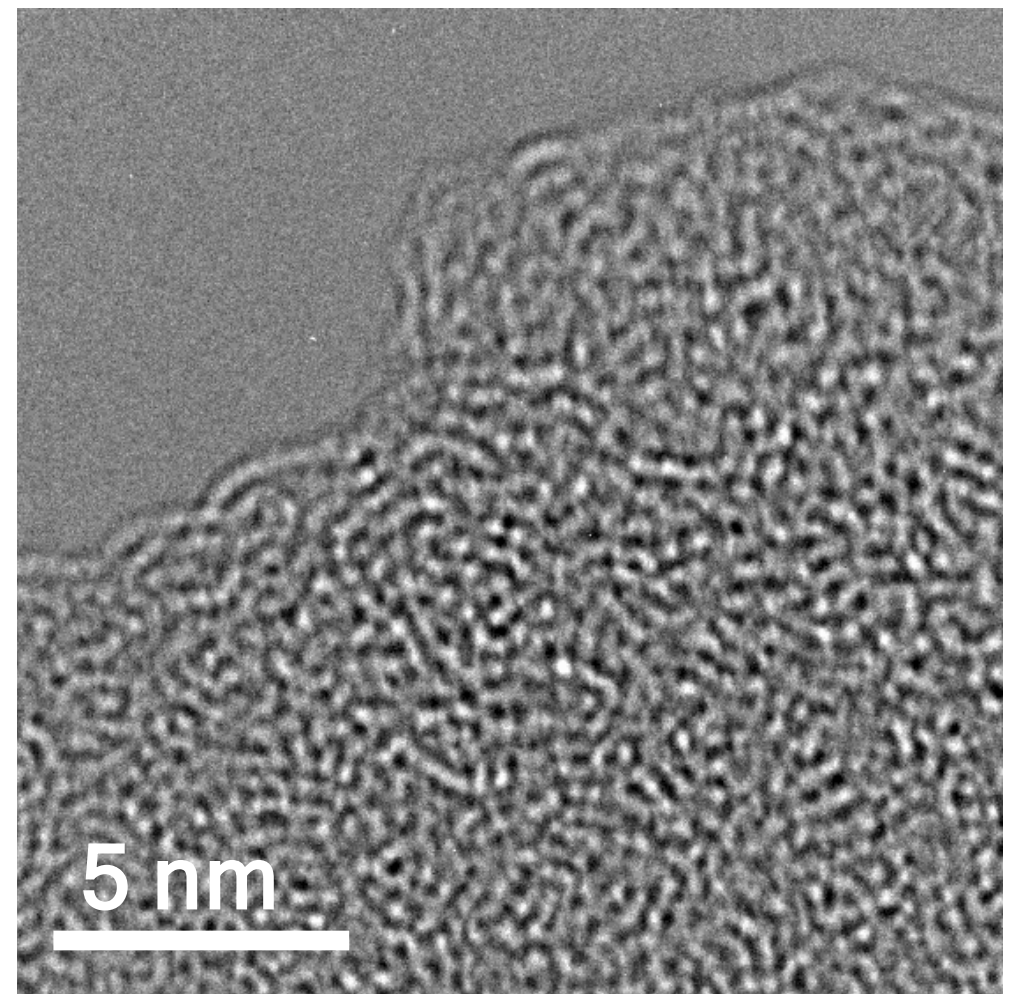

Figure S4. HRTEM image of NG-Heme. 

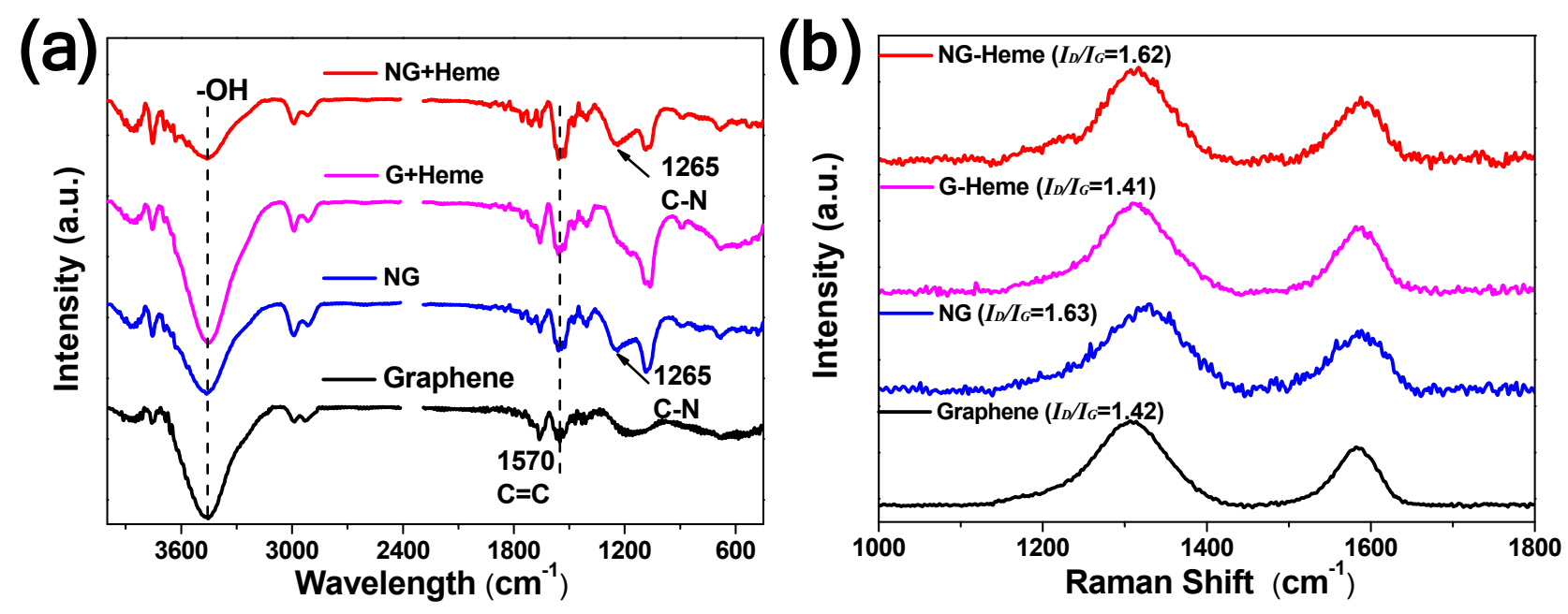

Figure S5. (a) FT-IR and (b) Raman spectra of graphene, NG, G-Heme and NG-Heme.
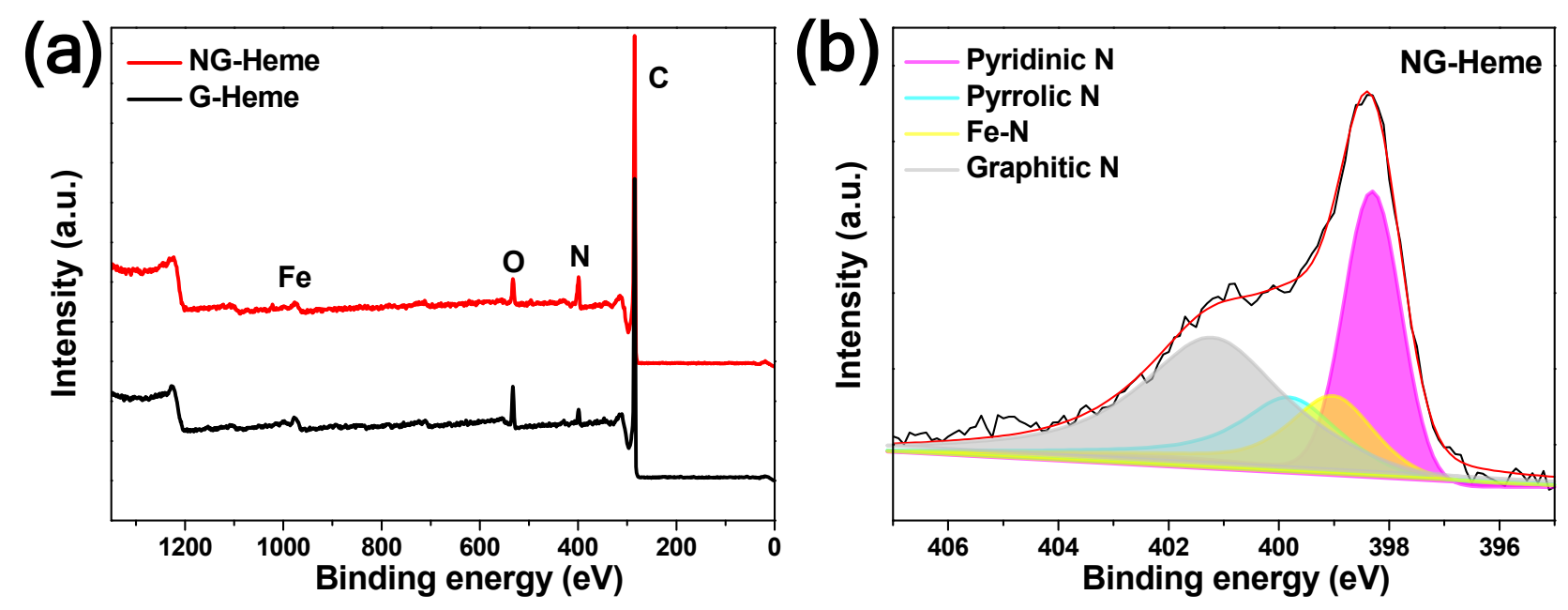

Figure S6. (a) Full range XPS spectra and (b) N 1s spectra of NG-Heme. 


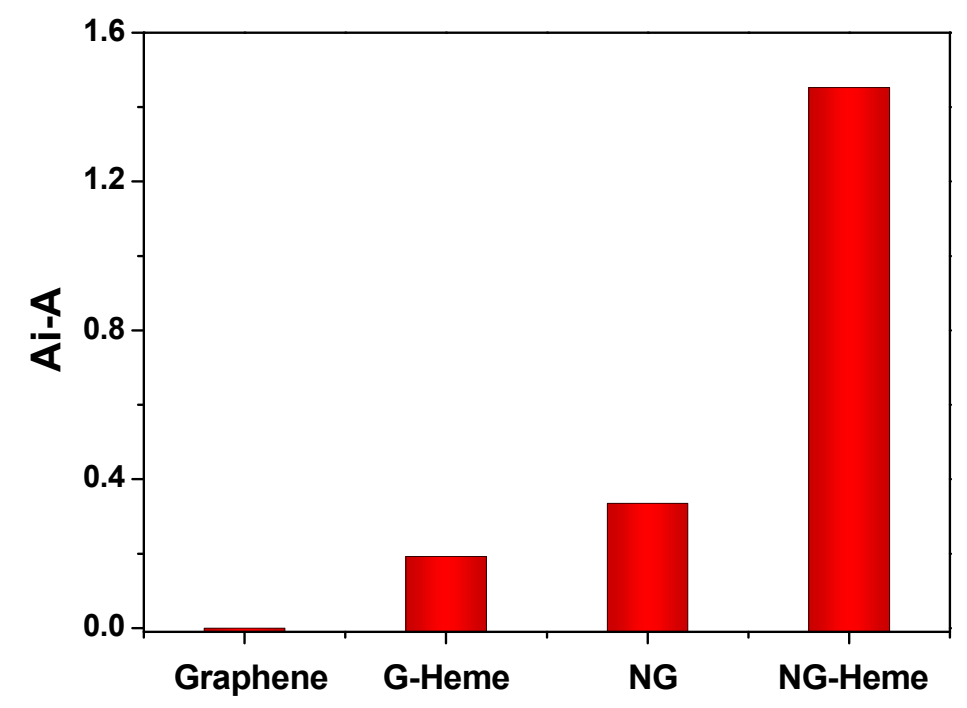

Figure S7. Relative enhanced absorbance values (Ai) of different catalysts toward graphene (A).

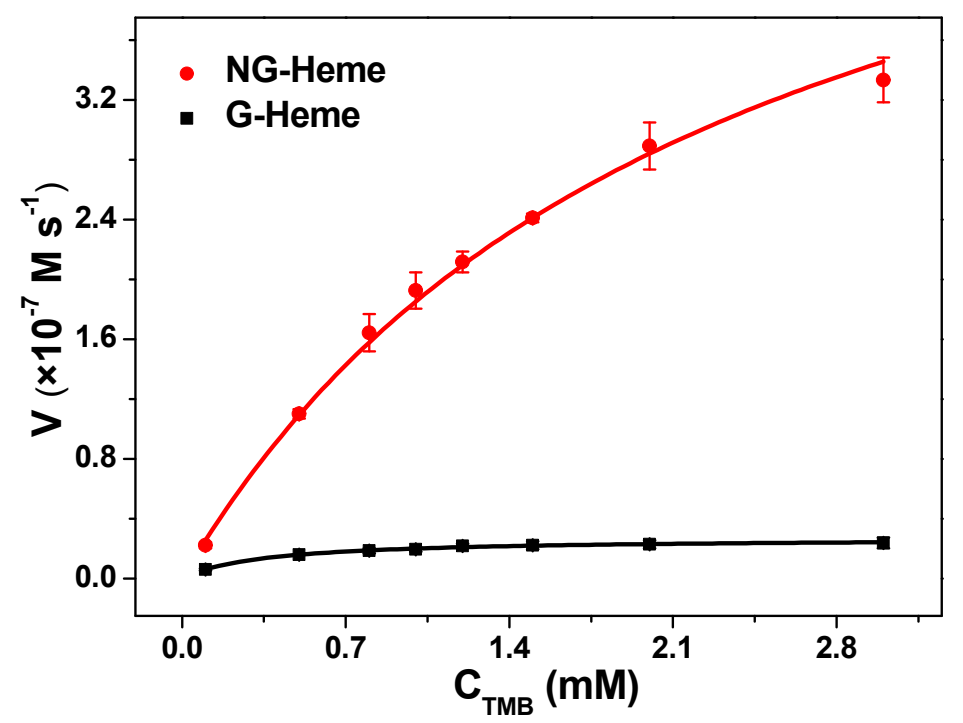

Figure S8. The kinetic curve of different SACs toward TMB. 

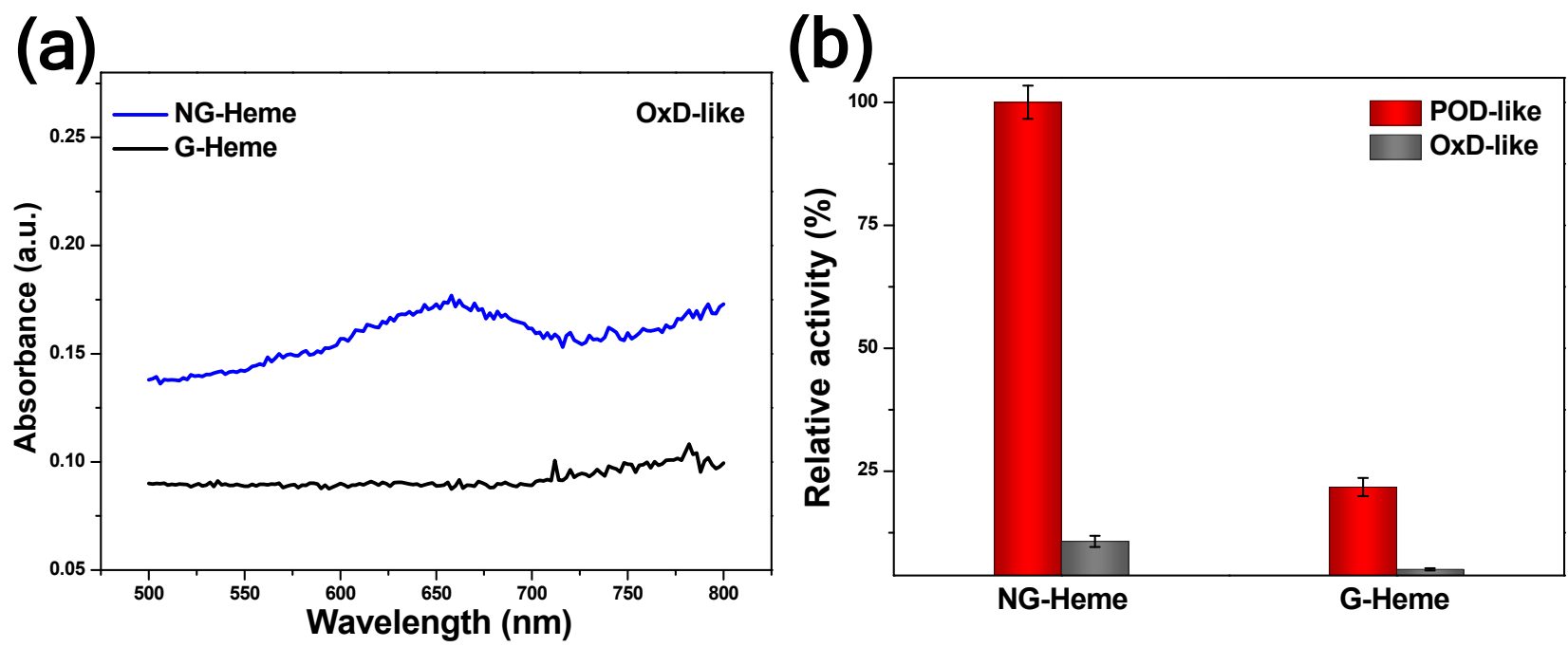

Figure S9. (a) Absorbance spectra of TMB catalyzed by G-Heme and NG-Heme. (b) Relative activity of POD and oxidase-like of G-Heme and NG-Heme.

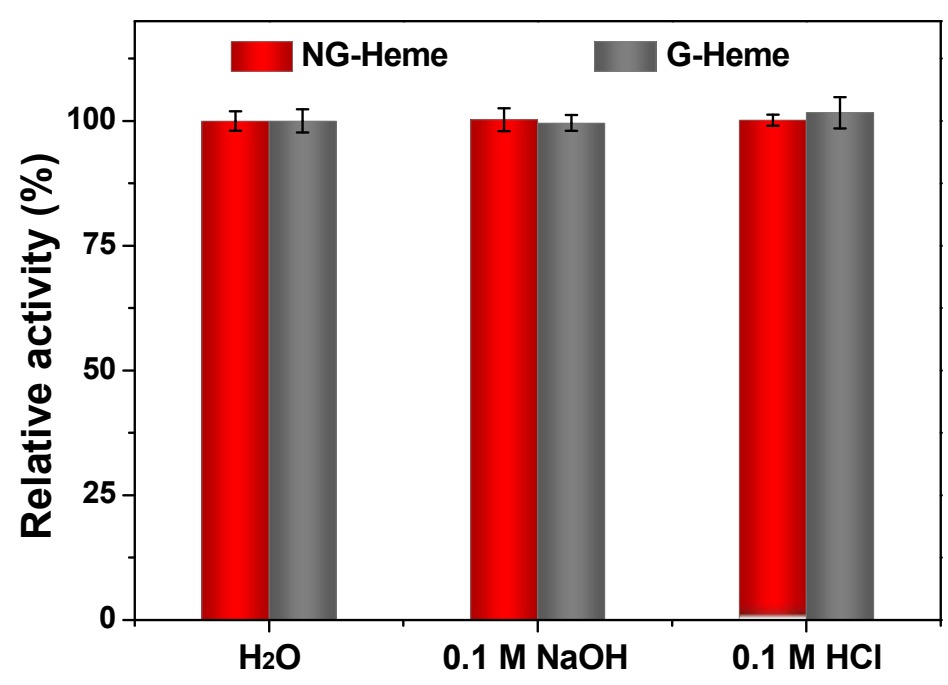

Figure S10. Acid-base tolerance of NG-Heme and G-Heme. 


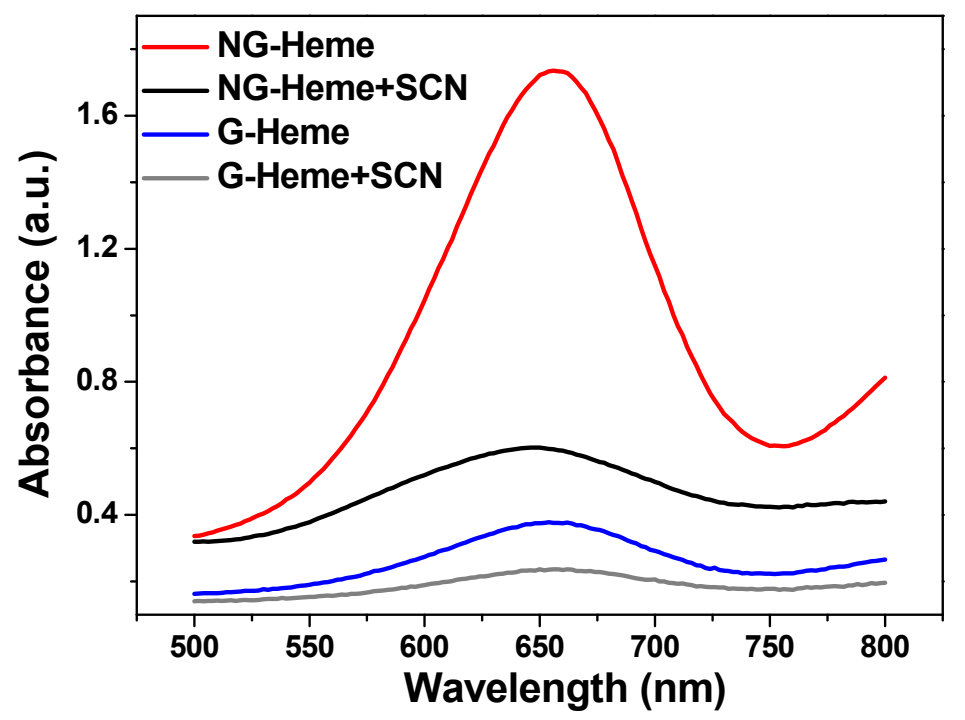

Figure S11. Absorbance spectra of TMB catalyzed by SACs before and after treatment with KSCN in the presence of $\mathrm{H}_{2} \mathrm{O}_{2}$.

(a)

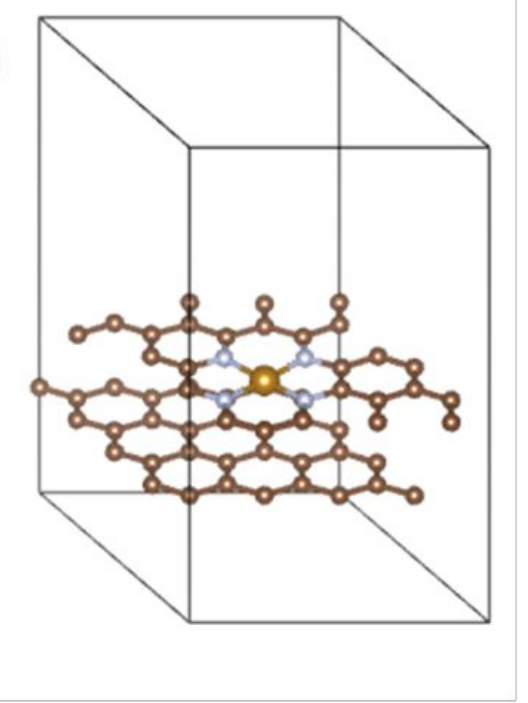

(b)

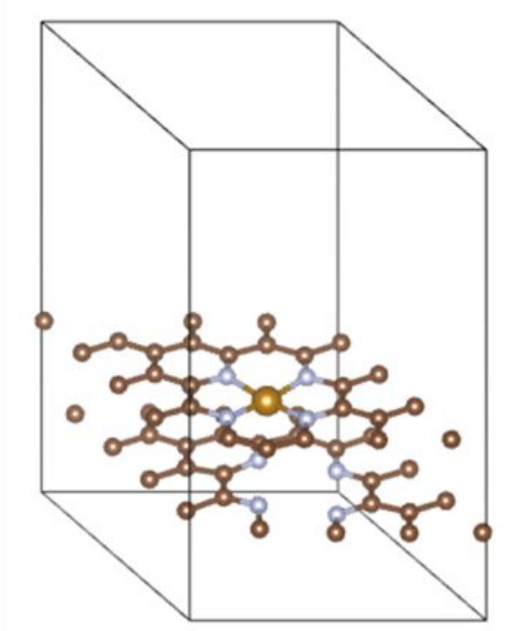

Figure S12. The side view of (a) G-Heme and (b) NG-Heme. 


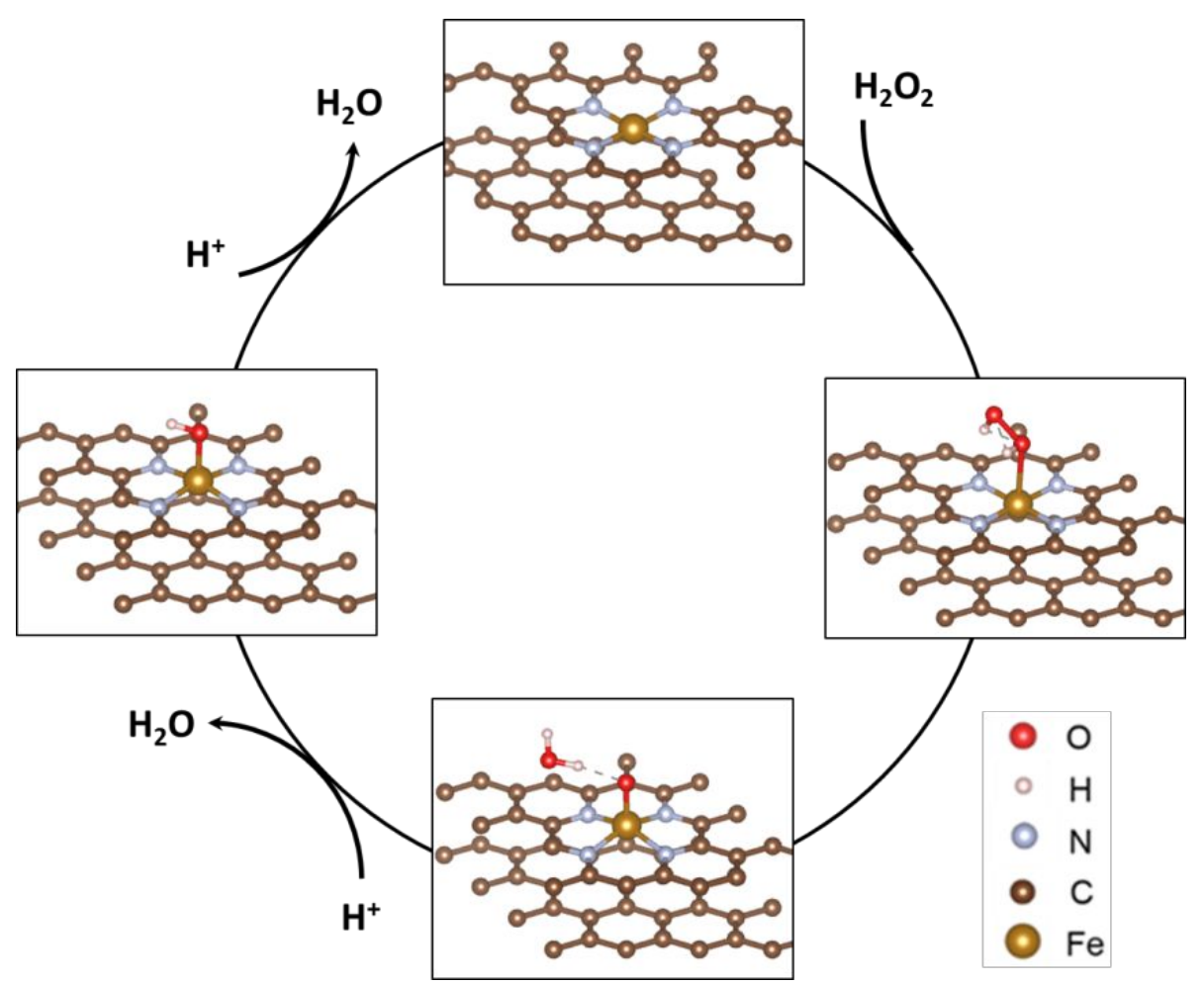

Figure S13. Schematic diagram of the elementary step of $\mathrm{H}_{2} \mathrm{O}_{2}$ reduction on G-Heme.

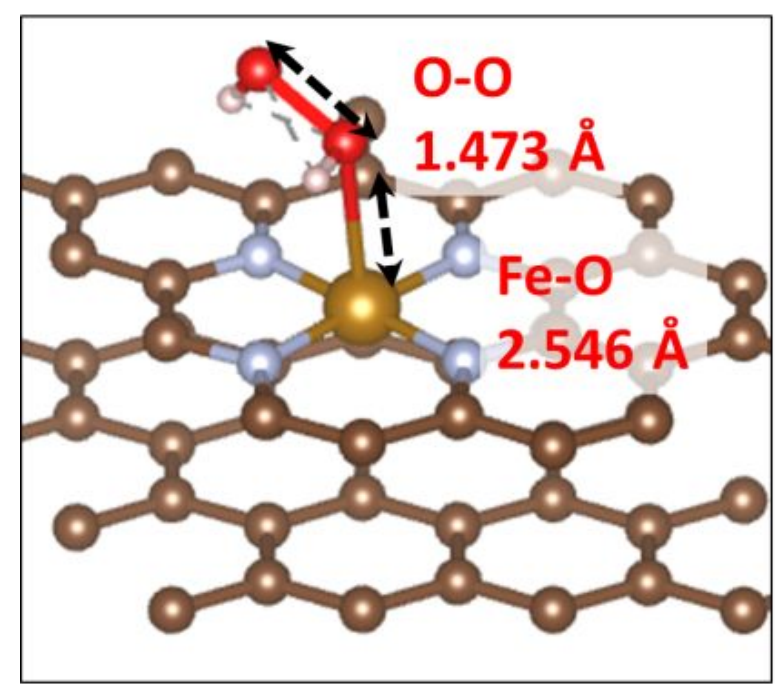

G-Heme

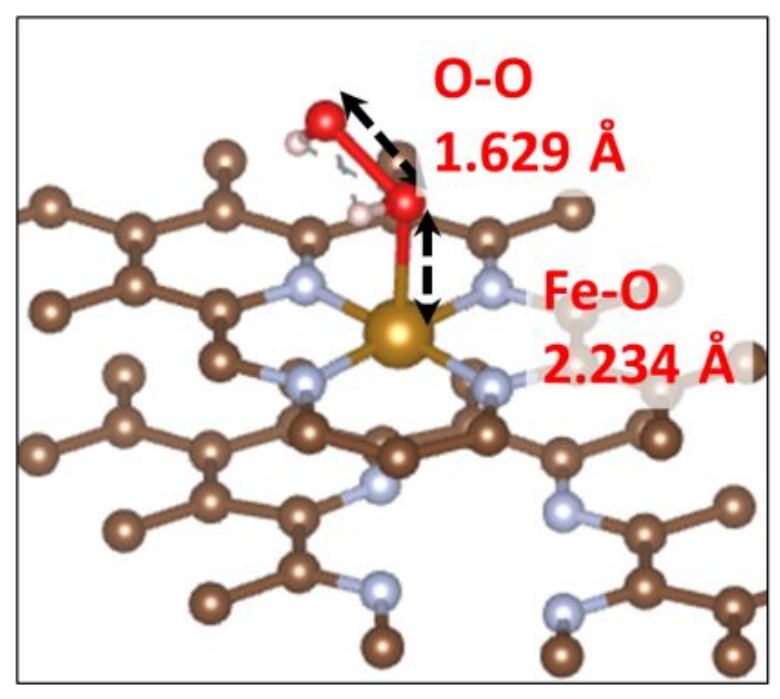

HG-Heme

Figure S14. The transition state structure of dehydration process of $\mathrm{H}_{2} \mathrm{O}_{2}$ on G-Heme and NG-Heme. 


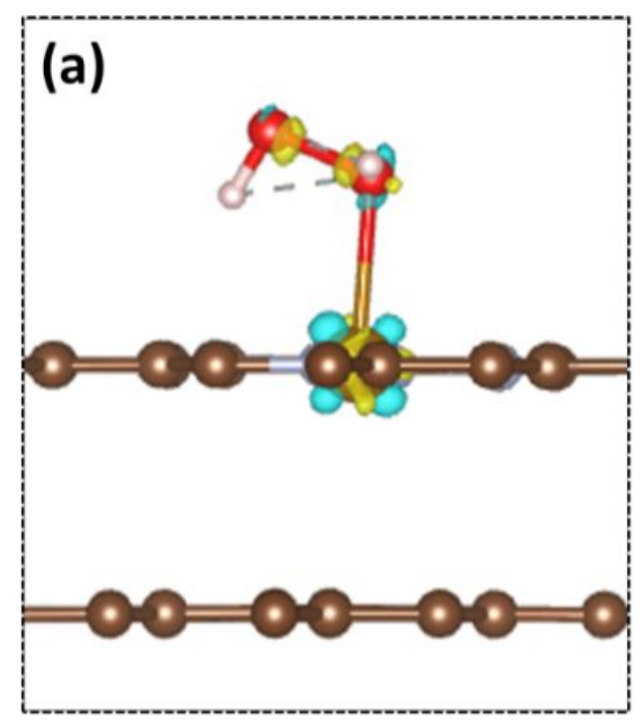

G-Heme

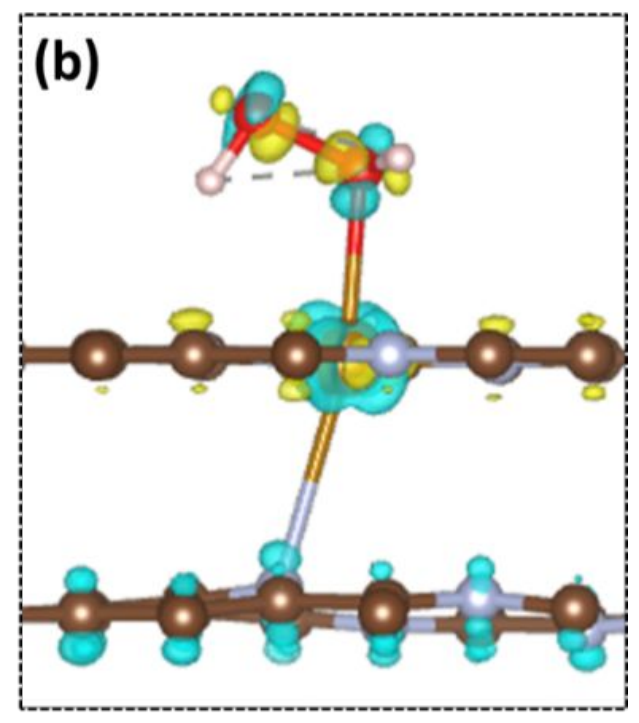

HG-Heme

Figure S15. Charge difference of $\mathrm{H}_{2} \mathrm{O}_{2}$ * adsorption state on (a) G-Heme and (b) NG-Heme, Yellow (blue) isosurfaces denote an increase (decrease) of electronic density.
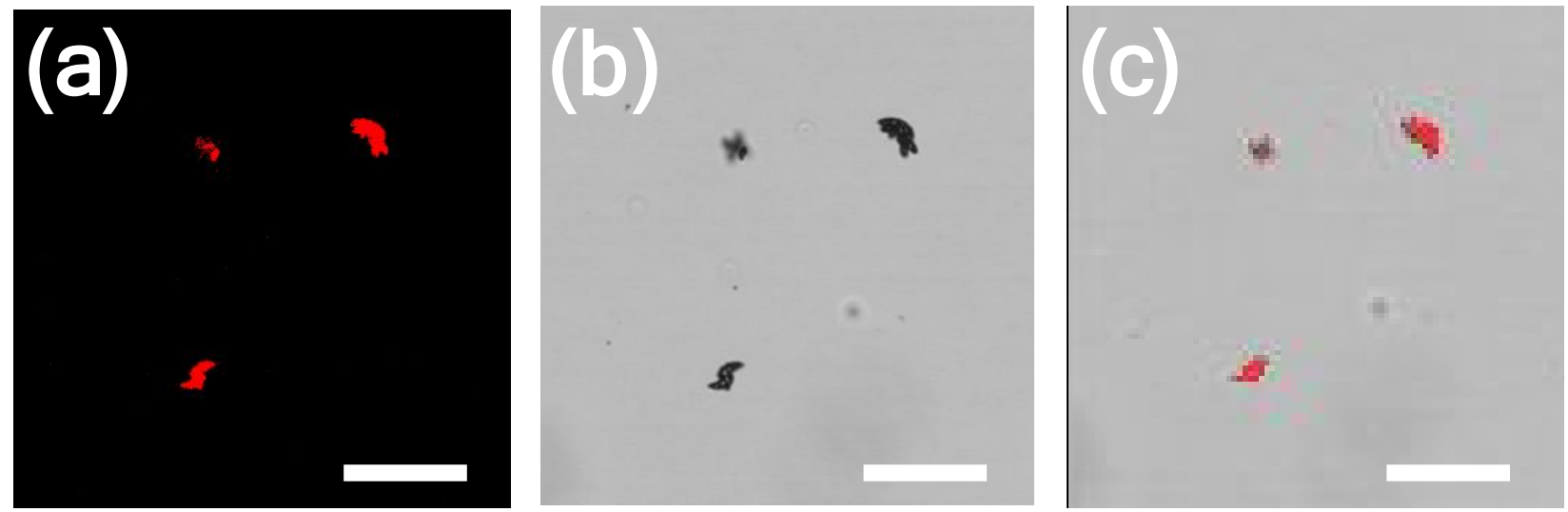

Figure S16. (a) Fluorescence images of RhB-labelled NG-Heme/Ab 2 excited at $488 \mathrm{~nm}$, (b) light field images of NG-Heme/Ab $\mathrm{Ab}_{2}$ and (c) the merged image of the above two images, scale bar, $10 \mu \mathrm{m}$. 

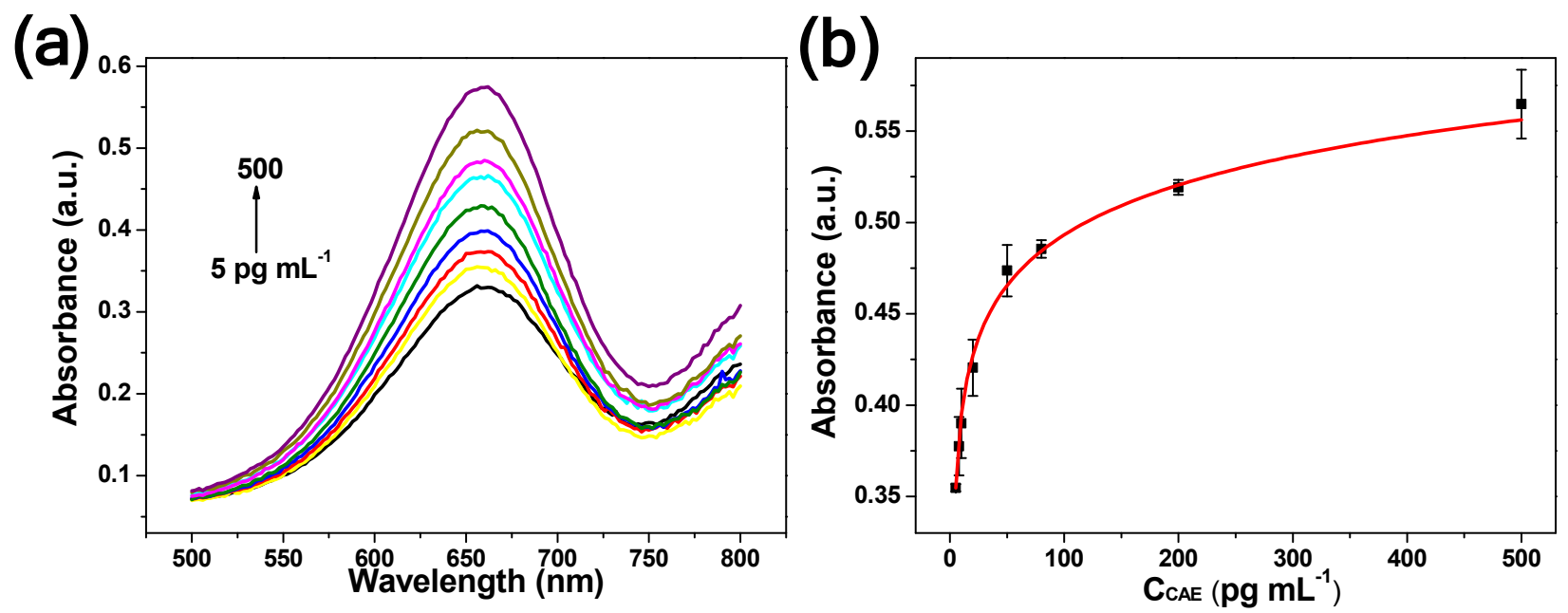

Figure S17. (a) Absorbance spectra of various concentrations CEA (from 5 to $500 \mathrm{pg} \mathrm{mL}-1$ ) detected by using the HRP-ELISA, and (b) corresponding Langmuir isotherm fitting curve between the absorbance intensity (at $652 \mathrm{~nm}$ ) and the amount of CEA.
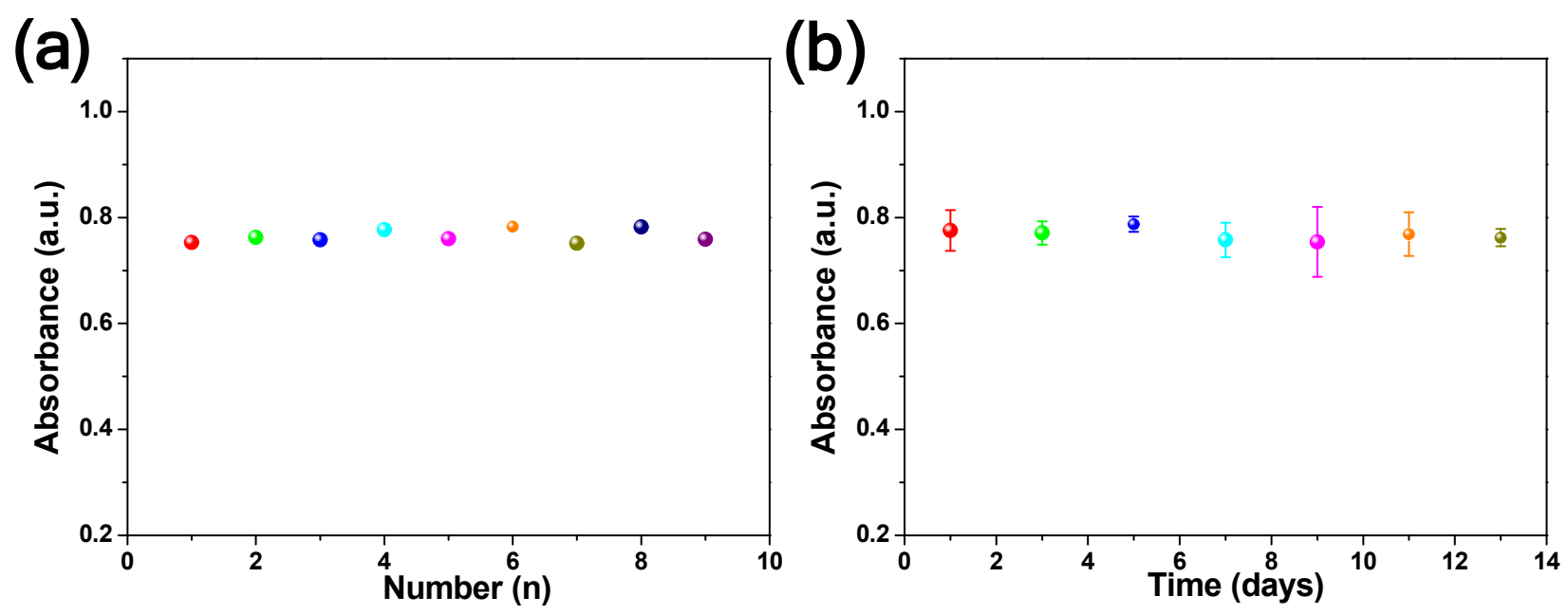

Figure S18. (a) Repeatability and (b) stability of constructed biosensor for the determination of CEA. 
Table S1 Contents of the different types N in NG-Heme.

\begin{tabular}{cc}
\hline & $\begin{array}{c}\text { Relative contents } \\
(\%)\end{array}$ \\
\hline Pyridinic & 54.6 \\
Fe-N & 18.5 \\
Pyrrolic & 18.7 \\
Graphitic & 8.2 \\
\hline
\end{tabular}

Table S2 EXAFS fitting parameters at the K-edge for various samples

\begin{tabular}{ccccccc}
\hline Sample & Shell & $\mathrm{N}$ & $\mathrm{R}(\AA)$ & $\sigma^{2}\left(\AA^{2}\right)$ & $\Delta \mathrm{E}_{0}(\mathrm{eV})$ & $\mathrm{R}$ factor $(\%)$ \\
\hline NG-Heme & Fe-N & 5.04 & 1.96 & 0.01357 & -3.709 & 0.026
\end{tabular}

$\mathrm{N}$ is coordination numbers, $\mathrm{R}$ is bond distance, $\sigma^{2}$ is Debye-Waller factors, $\Delta \mathrm{E}_{0}$ is the inner potential correction. $\mathrm{R}$ factor: goodness of fit. $\mathrm{S}_{0}{ }^{2}$ was obtained from the experimental EXAFS fit of foil references by fixing Fe-Fe as the known crystallographic value. 
Table $\mathrm{S3}$ The $\mathrm{V}_{\max }, \mathrm{K}_{\mathrm{m}}$ and catalytic constant $\left(\mathrm{K}_{\mathrm{cat}}=\mathrm{V}_{\max } /[\mathrm{E}]\right)$ of different SACs.

\begin{tabular}{|c|c|c|c|c|c|c|c|}
\hline Catalysts & {$[\mathrm{E}](\mu \mathrm{M})$} & Substrate & $\mathrm{K}_{\mathrm{m}}(\mathrm{mM})$ & $\begin{array}{c}\mathrm{V}_{\max }\left(\mathrm{x} 10^{-7}\right. \\
\left.\mathrm{M} \mathrm{s}^{-1}\right)\end{array}$ & $\mathrm{K}_{\mathrm{cat}}\left(\mathrm{s}^{-1}\right)$ & $\begin{array}{l}\mathrm{K}_{\mathrm{cat}} / \mathrm{K}_{\mathrm{m}} \\
\left(\mathrm{s}^{-1} \mathrm{M}^{-1}\right)\end{array}$ & Reference \\
\hline \multirow{3}{*}{ NG-Heme } & \multirow{3}{*}{2.97} & TMB & 2.29 & 6.02 & 0.20 & 87.34 & \multirow{3}{*}{ This work } \\
\hline & & & & & & & \\
\hline & & $\mathrm{H}_{2} \mathrm{O}_{2}$ & 21.64 & 1.67 & 0.056 & 2.58 & \\
\hline \multirow{3}{*}{ G-Heme } & \multirow{3}{*}{2.67} & TMB & 0.35 & 0.27 & 0.010 & 29.14 & \multirow{3}{*}{ This work } \\
\hline & & & & & & & \\
\hline & & $\mathrm{H}_{2} \mathrm{O}_{2}$ & 8.67 & 0.17 & 0.0064 & 0.74 & \\
\hline \multirow{3}{*}{$\mathrm{Fe}-\mathrm{N}-\mathrm{C}$} & \multirow{3}{*}{7.48} & TMB & 1.48 & 5.6 & 0.075 & 50.67 & \multirow{3}{*}[1]{} \\
\hline & & & & & & & \\
\hline & & $\mathrm{H}_{2} \mathrm{O}_{2}$ & 24.25 & 5.48 & 0.073 & 3.01 & \\
\hline \multirow{3}{*}{$\mathrm{Zn}-\mathrm{N}-\mathrm{C}$} & \multirow{3}{*}{48} & TMB & 0.224 & 10.66 & 0.0022 & 9.8 & \multirow{3}{*}{ [2] } \\
\hline & & & & & & & \\
\hline & & $\mathrm{H}_{2} \mathrm{O}_{2}$ & 40.16 & 12.15 & 0.0367 & 0.91 & \\
\hline \multirow{3}{*}{ Fe-MOF } & \multirow{3}{*}{49} & TMB & 2.6 & 0.56 & 0.0011 & 0.0042 & \multirow{3}{*}[3]{} \\
\hline & & & & & & & \\
\hline & & $\mathrm{H}_{2} \mathrm{O}_{2}$ & 1.3 & 0.25 & 0.0005 & 0.0004 & \\
\hline \multirow{3}{*}{$\mathrm{Fe}_{3} \mathrm{O}_{4} \mathrm{NPs}$} & \multirow{3}{*}{-} & TMB & 0.098 & 0.344 & - & - & \multirow{3}{*}[4]{} \\
\hline & & & & & & & \\
\hline & & $\mathrm{H}_{2} \mathrm{O}_{2}$ & 154 & 0.978 & - & - & \\
\hline
\end{tabular}

$[\mathrm{E}]$ is the concentration of metal atom, which is obtained from ICP-OES. 
Table S4 Comparison of different biosensors for the detection of CEA.

\begin{tabular}{|c|c|c|c|c|}
\hline Biosensor & Method & $\begin{array}{l}\text { Linear range (ng } \\
\left.\qquad \mathrm{mL}^{-1}\right)\end{array}$ & $\operatorname{LOD}\left(\mathrm{pg} \mathrm{mL}^{-1}\right)$ & References \\
\hline $\begin{array}{c}\mathrm{ITO} / \mathrm{WO}_{3} @ \mathrm{BiOI} @ \mathrm{Cd} \\
\mathrm{S}\end{array}$ & Photoelectrochemistry & $0.01-50$ & 3.2 & [3] \\
\hline $\begin{array}{c}\text { UCPs-CEA } \\
\text { aptamer-PdNPs }\end{array}$ & Fluorescence & $0.002-0.1$ & 0.8 & {$[4]$} \\
\hline $\begin{array}{l}\text { Oligonucleotide-funct } \\
\text { ionalized gold } \\
\text { nanorods (HO-GNRs) }\end{array}$ & Electrochemistry & $0.005-5$ & 1.5 & {$[5]$} \\
\hline AuNP & Colorimetry & $0.05-50$ & 48 & {$[6]$} \\
\hline NG-Heme & Colorimetry & $0.001-1$ & 0.55 & This work \\
\hline
\end{tabular}

Table S5 The recoveries of CEA in serum samples $(n=4)$.

\begin{tabular}{ccccc}
\hline Samples & $\begin{array}{c}\text { Spiked concentration } \\
(\mathrm{pg} / \mathrm{mL})\end{array}$ & $\begin{array}{c}\text { Measured concentration } \\
(\mathrm{pg} / \mathrm{mL})\end{array}$ & $\begin{array}{c}\text { Recovery } \\
(\%)\end{array}$ & RSD \% \\
\hline 1 & 5 & 4.95 & 98.95 & 0.57 \\
2 & 100 & 101.40 & 101.40 & 4.16 \\
3 & 200 & & & 4.92 \\
4 & 500 & 187.11 & 93.56 & 3.92 \\
\hline
\end{tabular}




\section{Reference}

(1) Jiao, L.; Xu, W.; Zhang, Y.; Wu, Y.; Gu, W.; Ge, X.; Chen, B.; Zhu, C.; Guo, S. Boron-doped Fe-N-C single-atom nanozymes specifically boost peroxidase-like activity. Nano Today, 2020, 35, 100971.

(2) Xu, B.; Wang, H.; Wang, W.; Gao, L.; Li, S.; Pan, X.; Wang, H.; Yang, H.; Meng, X.; Wu, Q.; Zheng, L.; Chen, S.; Shi, X.; Fan, K.; Yan, X.; Liu, H. A Single-Atom Nanozyme for Wound Disinfection Applications. Angew. Chem. Int. Ed. 2019, 58 (15), 4911-4916.

(3) Xu, W.; Jiao, L.; Yan, H.; Wu, Y.; Chen, L., Gu, W.; Du, D., Lin, Y., Zhu, C. Glucose Oxidase-Integrated MetalOrganic Framework Hybrids as Biomimetic Cascade Nanozymes for Ultrasensitive Glucose Biosensing. ACS Appl. Mater. Interfaces 2019, 11, 22096-22101.

(4) Gao, L., Zhuang, J., Nie, L., Zhang J., Zhang Y., Gu N., Wang T., Feng J., Yang D., Perrett S., Yan X. Intrinsic peroxidase-like activity of ferromagnetic nanoparticles. Nat. Nanotech. 2007, 2, 577-583.

(5) Han, Q.; Wang, R.; Xing, B.; Zhang, T.; Khan, M. S.; Wu, D.; Wei, Q. Label-free photoelectrochemical immunoassay for CEA detection based on $\mathrm{CdS}$ sensitized $\mathrm{WO}_{3} @ \mathrm{BiOI}$ heterostructure nanocomposite. Biosens Bioelectron. 2018, 99, 493-499.

(6) Li, H.; Shi, L.; Sun, D.-e.; Li, P.; Liu, Z. Fluorescence resonance energy transfer biosensor between upconverting nanoparticles and palladium nanoparticles for ultrasensitive CEA detection. Biosens. Bioelectron. 2016, 86, 791-798.

Wen, W.; Huang, J.-Y.; Bao, T.; Zhou, J.; Xia, H.-X.; Zhang, X.-H.; Wang, S.-F.; Zhao, Y.-D. Increased electrocatalyzed performance through hairpin oligonucleotide aptamer-functionalized gold nanorods labels and graphene-streptavidin nanomatrix: Highly selective and sensitive electrochemical biosensor of carcinoembryonic antigen. Biosens. Bioelectron.2016, 83, 142-148.

(8) Liu, M.; Jia, C.; Jin, Q.; Lou, X.; Yao, S.; Xiang, J.; Zhao, J. Novel colorimetric enzyme immunoassay for the detection of carcinoembryonic antigen. Talanta, 2010, 81 (4), 1625-1629. 